\title{
Induction of Differential Growth in vitro by High-risk Human Papillomavirus in Human Breast Cancer Cell Lines is Associated with Caspase Dysregulation
}

\begin{abstract}
Karl Kingsley ${ }^{1 \star \S}$, Jennifer Zuckerman ${ }^{2}$, Morghan Davis ${ }^{2}$, Matt Matteucci ${ }^{2}$, Aubrey Knavel ${ }^{2}$, Jacqueline Rinehart ${ }^{2}$,

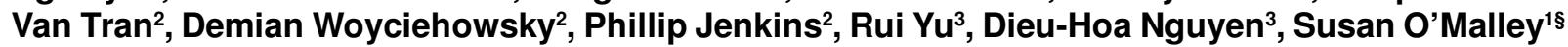

\author{
'Department of Biomedical Sciences, School of Dental Medicine, University of Nevada, Las Vegas \\ ${ }^{2}$ Department of Clinical Sciences, School of Dental Medicine, University of Nevada, Las Vegas \\ ${ }^{3}$ Department of Biological Sciences, University of Nevada, Las Vegas
}

$\S$ These authors contributed equally to this work

\begin{abstract}
\section{Introduction}

Many viruses have been associated with human breast cancers, including Epstein-Barr and Cytomegalovirus. New evidence has revealed the frequent presence of highrisk human papillomavirus (HPV) strains HPV16 and HPV18 in breast carcinoma biopsies. These findings raise the question of whether HPV may infect developing cancers and mediate their growth and development, as was recently observed with oral cancers. The goal of this study is to test the hypothesis that these high-risk HPV strains are sufficient to significantly alter phenotypes of already transformed human breast cancer cell lines.
\end{abstract}

\section{Materials and methods}

A series of in vitro experiments, including proliferation, adhesion and viability assays, were used to quantify the effects of HPV16 and HPV18 on the human breast cancer cell lines, T-47D and MCF7, following transient transfection with the full length HPV virus. Normal breast and fibroblast cell lines, MCF10A and Hs27, were used as noncancerous controls.

\section{Results}

HPV16 and HPV18 significantly inhibited proliferation and adhesion of T-47D cells, although viability was not affected. Differential effects on proliferation were observed in MCF7 cells; HPV16 inhibited proliferation, while HPV18 stimulated proliferation. No measurable effects in adhesion or viability in MCF7 cells were observed. The phenotypic changes in T-47D and MCF7 cells were associated with changes in mRNA expression of caspase- $2,-3$ and -8 , but not $\mathrm{p} 53$ or GAPDH. No measurable changes in proliferation or viability were observed following HPV transfection in the normal human breast cell line, MCF10A, or the normal human fibroblast cell line, Hs27, although adhesion was differentially affected.

\section{Conclusions}

Although HPV is a primary cause of virtually all cervical cancers, it is found as a concomitant infection in many other tumors. While HPV may initiate carcinogenesis in these tumors, recent studies suggest HPV may also modulate the progression or malignancy process in already transformed cancers. Determining what effects HPV has on already transformed breast cancers may therefore become an important step towards understanding the factors that will lead to more effective treatment options for a significant proportion of breast cancer patients.

Keywords: Breast cancer; Human papillomavirus

\section{Introduction}

Viruses, including Epstein-Barr, Cytomegalovirus, and Herpes simplex virus, have been implicated in the etiology of human breast cancers (Lawson et al., 2001; Lawson et al., 2006; Tsai et al., 2007). Recent evidence now suggests that high-risk human papillomavirus (HPV) strains HPV16 and HPV18, primarily associated with cervical cancers, are also present in as many as half of breast carcinoma biopsies (Kan et al., 2005; de Villiers et al., 2005). HPV has been implicated as the causative agent in many intraepithelial neoplasias and invasive squamous cell carcinomas, with the HPV16 and HPV18 strains most frequently observed, with HPV16 the most prevalent among noncervical cancers, such as oral and breast cancers (Herrero et al., 2003; Munoz et al., 2003; Kan et al., 2005; Smith et al., 2007).

Infection with high-risk HPV plays a central role in the carcinogenesis and etiology of nearly all cases of cervical cancer, therefore HPV may also function to transform oral and breast tissue (Walboomers et al., 1999; Kreimer et al., 2005; Syrjanen 2005). However, evidence from oral biopsies reveals a comparatively low presence of HPV in pre-malignant oral lesions $(10 \%)$, suggesting a role other than transformation (Kreimer et

\footnotetext{
*Corresponding author: Karl Kingsley, Department of Biomedical Sciences, School of Dental Medicine, University of Nevada, Las Vegas, Email: karl.kingsley@unlv.edu
}

Received October 28, 2009; Accepted November 30, 2009; Published November 30, 2009

Citation: Kingsley K, Zuckerman J, Davis M, Matteucci M, Knavel A, et al. (2009) Induction of Differential Growth in vitro by High-risk Human Papillomavirus in Human Breast Cancer Cell Lines is Associated with Caspase Dysregulation. J Cancer Sci Ther 1: 062-071. doi:10.4172/19485956.1000010

Copyright: () 2009 Kingsley K, et al. This is an open-access article distributed under the terms of the Creative Commons Attribution License, which permits unrestricted use, distribution, and reproduction in any medium, provided the original author and source are credited.

J Cancer Sci Ther
Volume 1(2) : 062-071 (2009) - 062 
Citation: Kingsley K, Zuckerman J, Davis M, Matteucci M, Knavel A, et al. (2009) Induction of Differential Growth in vitro by Highrisk Human Papillomavirus in Human Breast Cancer Cell Lines is Associated with Caspase Dysregulation. J Cancer Sci Ther 1: 062071. doi:10.4172/1948-5956.1000010

al., 2005; Syrjanen, 2005). More recent evidence demonstrates that high-risk HPV strains most commonly associated with these HPV-positive oral cancers significantly alters in vitro growth (Kingsley et al., 2006; Reddout et al., 2007). When combined with evidence that HPV is present only in a subset of oral cancers, these data imply that HPV infection may contribute to the malignancy process in existing or developing cancers, rather than acting as a primary factor for inducing carcinogenesis (Gillison et al., 2000; van Houten et al., 2001).

The recent detection of HPV in a subset of breast cancers raises the question of whether, in addition to a role in carcinogenesis, HPV may also preferentially infect already developing tumors and subsequently mediate their growth (Kan et al., 2005; de Villiers et al., 2005). New evidence to determine the specific role of HPV in breast carcinogenesis suggests HPV may be involved in the transformation process in a majority of the cases examined (Khan et al., 2008). However, these data further suggest that in a significant subset of cases, other factors were likely responsible for initiation of carcinogenesis and that HPV may have preferentially infected these tumors, but not the surrounding tissue. Based upon this information, this study was designed to understand what effects HPV may have on already existing breast cancer cells.

Researchers hypothesize that several of the same risk factors for developing cancer may also enhance the risk for acquiring HPV infection. The main risk factors associated with breast cancer include family history of disease, levels of hormones such as estrogen and progesterone, as well as cigarette smoking and alcohol consumption (Dean, 2008; Mahoney et al., 2008). These risk factors are not exclusive to breast cancer risk and may also be strongly linked with HPV infection.

Interestingly, one recent study found that two HPV genes, E6 and E7, were sufficient to induce changes to metastatic phenotypes in MCF7 and BT20 breast cancer cells, in vitro and in vivo (Yasmeen et al., 2007a; Yasmeen et al., 2007b). To date, no studies have yet examined the effects of the full-length HPV16 or HPV18 virus on the proliferative phenotype of established breast cancers. This study is among the first to provide direct evidence that elucidates the ability of HPV infection to alter the proliferative phenotype of breast cancers in vitro.

\section{Materials and Methods}

\section{Cell culture}

The human breast cancer cell lines used in this study, MCF7 (HTB-22) and T-47D (HTB-133), as well as the non-tumorigenic epithelial breast cell line MCF10A(CRL-10317) and normal human fibroblast cell line Hs27 (CRL-1634), were obtained from American Type Culture Collection (ATCC: Manassas, VA). In addition, CaSki (CRL-1550: epidermoid carcinoma, cervix) and GH354 (CRL-13003: human cervical adenocarcinoma) were also obtained from ATCC as HPV 16 and HPV18 positive controls, respectively. Hs27 fibroblast control and GH354 cervical adenocarcinoma cells were maintained in Dulbecco's Modified Eagle's Medium (DMEM) with $4 \mathrm{mM}$ L-Glutamine, adjusted to contain $3.7 \mathrm{~g} / \mathrm{L}$ sodium bicarbonate and $4.5 \mathrm{~g} / \mathrm{L}$ glucose, from Hyclone (Logan, UT). T-47D and CaSki cells were maintained in RPMI-1640 medium with 2mM L-Glutamine, adjusted to contain $1.5 \mathrm{~g} / \mathrm{L}$ sodium bicarbonate, $4.5 \mathrm{~g} / \mathrm{L}$ glucose, $10 \mathrm{mM}$ J Cancer Sci Ther
HEPES, and 1.0 mM sodium pyruvate. MCF7 cells were maintained in Minimum Essential Medium (MEM) with $2.00 \mathrm{mM}$ L-Glutamine with Earle's Balanced Salts. MCF10A breast control cells were maintained in DME/F-12 with $2.50 \mathrm{mM} \mathrm{L}$ Glutamine and $15 \mathrm{mM}$ HEPES buffer with $0.5 \mathrm{mg} / \mathrm{ml}$ hydrocortisone, $10 \mu \mathrm{g} / \mathrm{mLEGF}, 5 \mathrm{mg} / \mathrm{ml}$ insulin and $100 \mathrm{ng} / \mathrm{ml}$ cholera toxin. Media for all cell lines were supplemented with $10 \%$ fetal bovine serum (FBS), and with 1\% Penicillin (10,000 units/ $\mathrm{mL})$-Streptomycin $(10,000 \mu \mathrm{g} / \mathrm{ml})$ solution (HyClone), except GH354 which was supplemented with 20\% FBS and 1\% Penicillin-Streptomycin. Cell cultures were maintained in $75 \mathrm{~cm}^{2}$ BD Falcon tissue-culture treated flasks (Bedford, MA) at $37^{\circ} \mathrm{C}$ and $5 \% \mathrm{CO}_{2}$ in humidified chambers.

\section{HPV screening}

To determine if these cell lines already harbor HPV, DNA was isolated from $1.5 \times 10^{7}$ cells from each cell line using the GenomicPrep DNA isolation kit (Amersham Biosciences: Buckinghamshire, UK), using the procedure recommended by the manufacturer. To confirm the absence of HPV DNA in each cell line prior to transfection and presence of HPV DNA in each cell line post-transfection, PCR was performed with the Fisher exACTGene complete PCR kit (Fisher Scientific: Fair Lawn, NJ) and a Mastercycler gradient thermocycler (Eppendorf: Hamburg, Germany) using the following primers synthesized by SeqWright (Houston, TX):

HPV18 forward primer, ATGGCGCGCTTTGAGGATCC; HPV18 reverse primer, GCATGCGGTATACTGTCTCT; HPV16 forward primer, ATGTTTCAGGACCCACAGGA; HPV16 reverse primer, CCTCACGTCGCAGTAACTGT.

One $\mu g$ of template DNA was used for each reaction. The initial denaturation step ran for 1 minute at $94^{\circ} \mathrm{C}$. Thirty amplification cycles were run, consisting of 30 second denaturation at $94^{\circ} \mathrm{C}, 60$ seconds of annealing at $58^{\circ} \mathrm{C}$, and 6.5 minutes of extension at $68^{\circ} \mathrm{C}$. Final extension was run for 5 minutes at $68^{\circ} \mathrm{C}$. Reaction products were separated by gel electrophoresis using Reliant 4\% NuSieve® 3:1 Plus Agarose gels (Lonza: Rockland, ME). Bands were visualized by UV illumination of ethidium-bromide-stained gels and captured using a Kodak Gel Logic 100 Imaging System and 1D Image Analysis Software (Eastman Kodak: Rochester, NY).

\section{Transfection}

MCF7 (HTB-22), T-47D (HTB-133), MCF10A(CRL-10317) and Hs27 (CRL-1634) cells were transfected with HPV16 and HPV18. Briefly, cells were seeded in $25 \mathrm{~cm}^{2}$ BD Falcon tissueculture treated flasks in appropriate media (as described) and allowed to achieve $70 \%$ confluence. Cells were then transiently transfected by adding $1 \mu \mathrm{g} / \mathrm{ml}$ of full-length HPV type 16 , cloned into the pBluescript SK-vector (ATCC \#45113) or HPV type 18 , cloned into the pBR322 vector (ATCC \#45152). The transfections were performed using the Stratagene Mammalian Transfection Kit (La Jolla, CA) according to the manufacturer's recommended protocol for $\mathrm{CaPO}_{4}$ transfection. Mock transfectants (mTF) of these four cell lines were also established by performing the same transfection protocol, but without using virus (empty vector).

To test the effectiveness of the transient transfections, RNA

ISSN:1948-5956 JCST, an open access journal

Volume 1(2) : 062-071 (2009) - 063 


\section{Journal of Cancer Science \& Therapy - Open Access \\ JCST/Vol.1 Issue 2}

was isolated from $1.5 \times 10^{7}$ cells of each of the experimental and control cell lines, using ABgene Total RNA Isolation Reagent (Epsom, Surrey, UK) and the procedure recommended by the manufacturer. To quantify the expression of HPV mRNA, RT-PCR was performed on total RNA using the ABgene Reverse-iT One-Step RT-PCR Kit (ReadyMix Version) and a Mastercycler gradient thermocycler (Eppendorf: Hamburg, Germany) using the HPV18 and HPV16 primers synthesized by SeqWright (Houston, TX).

One $\mu \mathrm{g}$ of template (total) RNA was used for each reaction. The reverse transcription step ran for 30 minutes at $47^{\circ} \mathrm{C}$, followed by denaturation for 2 minutes at $94^{\circ} \mathrm{C}$. Thirty-five amplification cycles were run, consisting of 20 second denaturation at $94^{\circ} \mathrm{C}, 30$ seconds of annealing at $58^{\circ} \mathrm{C}$, and 6.5 minutes of extension at $72^{\circ} \mathrm{C}$. Final extension was run for 5 minutes at $72^{\circ} \mathrm{C}$. Reaction products were separated by gel electrophoresis using Reliant 4\% NuSieve® 3:1 Plus Agarose gels (Lonza: Rockland, $\mathrm{ME}$ ). Bands were visualized by UV illumination of ethidiumbromide-stained gels and captured using a Kodak Gel Logic 100 Imaging System and 1D Image Analysis Software (Eastman Kodak: Rochester, NY). Quantitation of RT-PCR band densitometry and relative mRNA expression levels was performed using Adobe Photoshop (San Jose, CA) imaging software, Image Analysis tools.

\section{Proliferation}

Proliferation assays were performed with MCF7, T-47D, MCF10A, and Hs 27 cells with the appropriate complete media in Corning Costar 96-well assay plates (Corning, NY), using HPV16 or HPV18 transfected cells, mock-transfected cells, and non-transfected controls. Cells were seeded at a concentration of $1.2 \times 10^{4}$ cells per well and proliferation was measured over three days at four time points (day 0 - day 3), as previously described (Kingsley et al., 2006; Reddout et al., 2007). Cultured cells were fixed at each time point, 0 hours (day 0), 24 hours (day 1), 48 hours (day 2), and 72 hours (day 3), using 50 $\mu 1$ of $10 \%$ buffered formalin and subsequently stained with crystal violet $1 \%$ aqueous solution (Fisher Scientific: Fair Lawn, $\mathrm{NJ}$ ). Relative absorbance was then measured at $630 \mathrm{~nm}$ using a Bio-Tek ELx808 microplate reader (Winooski, VT) and data were analyzed and graphed using Microsoft Excel (Redmond, WA) and SPSS (Chicago, IL). Three separate, independent replications of each experiment were performed.

\section{Adhesion}

Adhesion assays were performed at a concentration of $1.2 \mathrm{x}$ $10^{5}$ cells per well $\left(100 \mu \mathrm{l}\right.$ of $1.2 \times 10^{6}$ cells $/ \mathrm{ml}$ solution suspended in serum-free DMEM, MEM, DME:F-12 or RPMI with no additives) in uncoated Corning Costar 96-well assay plates (Corning, NY) as previously described (Plopper et al., 1995; Wagner et al., 2002; Reddout et al., 2007). Cells were allowed to attach for 30 minutes at $37^{\circ} \mathrm{C}$ with one modification to the standard adhesion assay. The modified adhesion assays used in this study eliminated the plate suspension step, in which nonadherent cells are generally removed by suspending the plate upside-down in a rotating tank of PBS, which greatly enhances the sensitivity of this assay, as previously described (Kingsley et al., 2006). Following the incubation period, the cells were fixed using $50 \mu \mathrm{l}$ of $10 \%$ buffered formalin and subsequently stained with crystal violet $1 \%$ aqueous solution (Fisher Scien- tific: Fair Lawn, NJ). Relative absorbance was then measured at $630 \mathrm{~nm}$ using a Bio-Tek ELx808 microplate reader (Winooski, VT) and data were analyzed and graphed using Microsoft Excel (Redmond, WA). Three separate, independent replications of each assay were performed.

\section{Viability}

Prior to plating cells for adhesion and proliferation assays, aliquots of trypsinized cells were stained using Trypan Blue (Sigma: St. Louis, MO), and live cells were enumerated by counting the number of Trypan-blue negative cells using a VWR Scientific Counting Chamber (Plainfield, NJ) and a Zeiss Axiovert 40 inverted microscope (Gottingen, Germany). At each time point (day 0-3), several wells were processed using the Trypan stain, and live cells were enumerated using this procedure (Felsher et al., 2000; Kingsley et al., 2002).

\section{RT-PCR}

RNA was isolated from $1.5 \times 10^{7}$ cells of each of the experimental and control cell lines, using ABgene Total RNA Isolation Reagent (Epsom, Surrey, UK) and the procedure recommended by the manufacturer three days after transfection. RTPCR was performed on total RNA using the ABgene ReverseiT One-Step RT-PCR Kit (ReadyMix Version) and a Mastercycler gradient thermocycler (Eppendorf: Hamburg, Germany), as described above. The following primers for $\mathrm{p} 53$ (Vakifahmetoglu et al., 2006), caspase-2 and caspase-3 (Kugu et al., 1998), caspase-8 (Ruiz-Ruiz et al., 2004), and glyceraldehyde-3- phosphate dehydrogenase (GAPDH) (Wolter et al., 2003), synthesized by SeqWright (Houston, TX), were used:

p53 forward primer, ACCAGGGCAGCTACGGTTTC; p53 reverse primer, CCTGGGCATCCTTGAGTTCC; caspase-2 forward primer, TGGCATATAGGTTGCAGTCTC GG;

caspase-2 reverse primer, TGTTCTGTAGGCTTGGGCA GTTG;

caspase-3 forward primer, ACATGGAAGCGAATCAATG GACTC;

caspase-3 reverse primer, AAGGACTCAAATTCTGTTG CCACC;

caspase-8 forward primer, GATATTGGGGAACAACTGGAC; caspase- 8 reverse primer, CATGTCATCATCCAGTTTGCA; GAPDH forward primer, ATCTTCCAGGAGCGAGATCC; GAPDH reverse primer, ACCACTGACACGTTGGCAGT;

Bands were visualized by UV illumination of ethidium-bromide-stained gels and captured using a Kodak Gel Logic 100 Imaging System and 1D Image Analysis Software (Eastman Kodak: Rochester, NY). Quantitation of RT-PCR band densitometry was performed using Adobe Photoshop (San Jose, CA) imaging software, Image Analysis tools.

\section{Statistics}

The differences between treatments were measured using a $t$ distribution $(\alpha=0.05)$. All samples were analyzed using twotailed $t$-tests, as departure from normality can make more of a difference in a one-tailed than in a two-tailed $t$-test. As long as the sample size is even moderate ( $>20$ for each group), quite severe departures from normality make little practical difference in the conclusions reached from these analyses (Hays, 
Citation: Kingsley K, Zuckerman J, Davis M, Matteucci M, Knavel A, et al. (2009) Induction of Differential Growth in vitro by Highrisk Human Papillomavirus in Human Breast Cancer Cell Lines is Associated with Caspase Dysregulation. J Cancer Sci Ther 1: 062071. doi:10.4172/1948-5956.1000010

1994). However, analyses involving multiple two sample $t$-tests have a higher probability of Type I error, leading to false rejection of the null hypothesis, $\mathrm{H}_{0}$ (Hays, 1994). To confirm the effects observed from these experiments and minimize the possibility of Type I error, further analysis of the data was facilitated with ANOVA using SPSS (Chicago, IL) to more accurately assess relationships and statistical significance among and between groups.

\section{Results \\ HPV screening}

To confirm that each cell line did not already harbor HPV, DNA was isolated from cultured cells and PCR performed using primers specific for HPV16 and HPV18. In addition, two HPV-positive cervical cancer cell lines, CaSki (HPV16) and 1). These results demonstrated that T-47D, MCF7, MCF10A, and Hs27 were not found to contain endogenous HPV, while confirming that CaSki and GH354 harbor HPV16 and HPV18, respectively. Furthermore, the presence of HPV DNA was not observed in mock transfectants, but could be verified post-transfection.

\section{Transfection}

Effectiveness of the transient transfections and expression of HPV mRNA was assessed by performing RT-PCR on total RNA isolated from each cell line post-transfection and on the cell lines known to harbor endogenous HPV (CaSki, GH354). These results demonstrate that each HPV16-transfectants (Hs27-

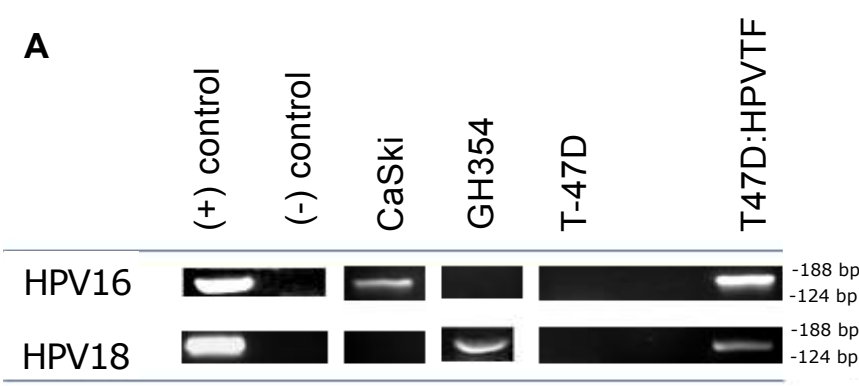

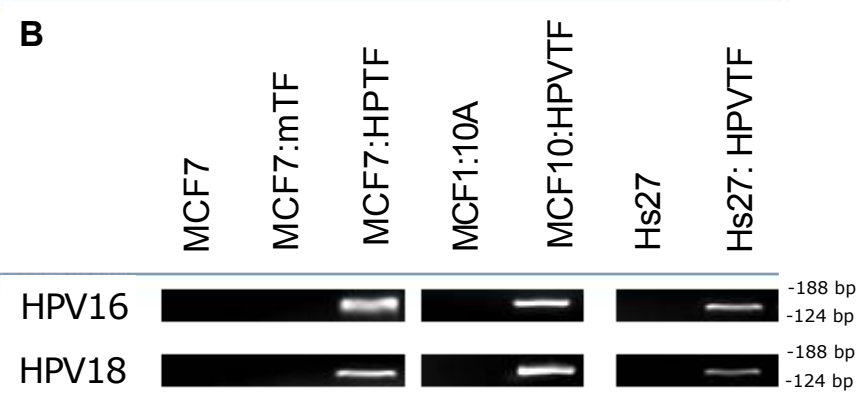

Figure 1: HPV was detectable in experimental cell lines only after transfection.

(A) PCR from total DNA demonstrated that CaSki and GH354 contain HPV16 and HPV18 specific sequences, respectively. PCR from total DNA of experimental cell lines confirms T-47D (A), MCF7, MCF10A and Hs27 (B) do not harbor these HPV-specific sequences. Following transfection with the fullquences, but not among mock transfectants (empty vector), such as T-47D mTF (A) or MCF7 mTF (B). GH354 (HPV18), were included as positive controls (Figure HPV16 and MCF10A-HPV16), expressed roughly equivalent length HPV genome, each cell was found to contain HPV16 or HPV18 se-

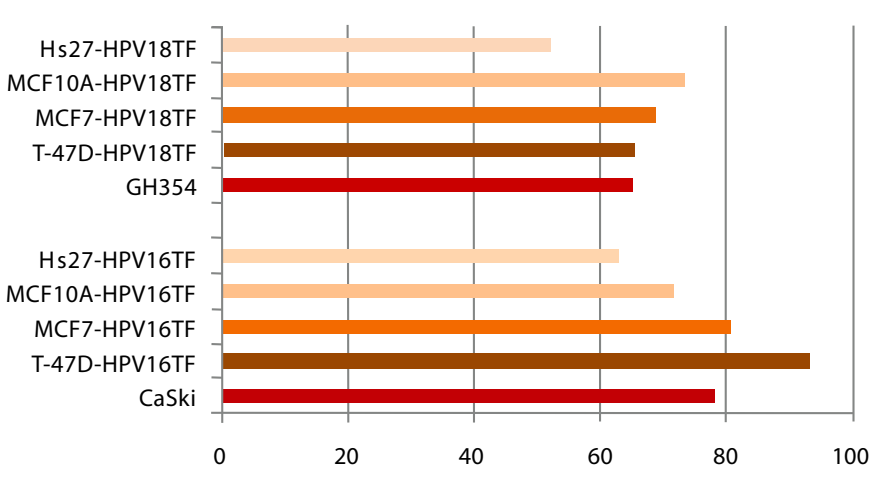

Relative HPV mRNA expression (arb. units)

Figure 2: HPV expression in vitro was comparable among transfectants. RT-PCR confirmed HPV expression in all four cell lines (T-47D, MCF7, MCF10A and Hs27) following HPV16 or HPV18 transfection. Scanning densitometry measurement of relative endpoint RT-PCR band intensities from all HPV18-transfectants were comparable, although lower than endogenous HPV expression from GH354 cells (top). HPV mRNA expression in T-47D and MCF7 HPV16-transfectants were roughly equivalent to endogenous expression from CaSki cells, and slightly higher than expression in normal cells, Hs27 and MCF10A (bottom).

amounts of virus mRNA, while MCF7-HPV16 andT-47DHPV 16 had slightly higher HPV mRNA expression profiles (Figure 2). Comparison with CaSki HPV16-specific mRNA reveals that endogenous HPV expression was approximately equivalent to the transfectants, although slightly lower among the normal cell lines. HPV18-transfectants (Hs27-HPV18, MCF10A-HPV18, MCF7-HPV18, and T-47D-HPV18) expressed roughly equivalent amounts of virus mRNA, while comparison with GH354 HPV18-specific mRNA revealed that endogenous HPV mRNA expression was slightly higher than that of HPV18 transfectants.

Previous studies with oral cancers revealed that transfection with the full-length HPV16 and HPV18 genome significantly altered cellular proliferation, adhesion, and viability. To test the hypothesis that HPV16 and HPV18 strains similarly alter the phenotypes of breast cancer cells, in vitro assays were performed following transfection with HPV16 and HPV18.

\section{HPV inhibited proliferation and adhesion in T-47D cells}

Transfection of T-47D cells with HPV16 resulted in lower proliferation compared with non-transfected controls $(-42 \%)$, as did HPV18 $(-39 \%)(\mathrm{p}<0.01, \mathrm{n}=216)$ (Figure 3A). Because these analyses involved multiple two-sample $t$-tests and a higher probability of Type I error, ANOVA was performed. This analysis confirmed that both HPV16 and HPV18 inhibited cellular proliferation in T-47D cells. T-47D-HPV16 proliferation was not significantly different from T-47D-HPV18 proliferation, however, they were both significantly different from the mock and non-transfected controls.

Based upon the results of the proliferation assay, we sought to determine if this response correlated with measurable alterations to cellular adherence or cellular viability. Baseline T47D adhesion (without HPV) was significantly reduced by both HPV16 $(-16 \% ; \mathrm{n}=72, \mathrm{p}<0.01)$ and HPV18 $(-15 \% ; \mathrm{n}=72, \mathrm{p}<0.01)$ (Figure 3B), although measurements of cell survival and viability revealed no significant differences between groups (Table 1).

J Cancer Sci Ther 


\section{Journal of Cancer Science \& Therapy - Open Access \\ JCST/Vol.1 Issue 2}

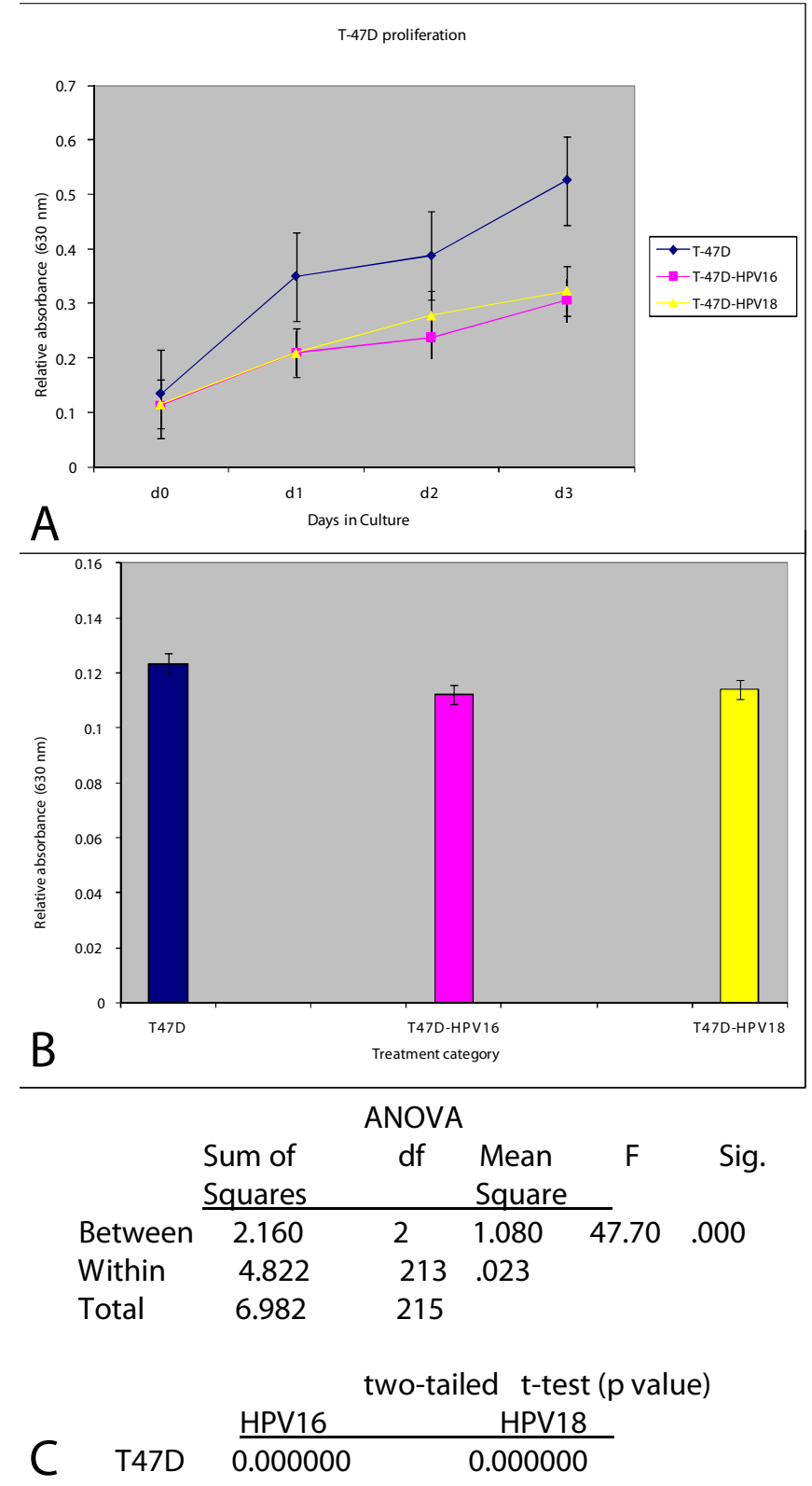

Figure 3: Proliferation and adhesion of T-47D cells was significantly inhibited by HPV16 or HPV18 in vitro.

HPV-transfected and control T-47D cells were plated in 96-well assay plates with media containing $10 \%$ FBS and were allowed to proliferate for three days. (A) HPV16 and HPV18 transfected cells exhibited reduced proliferation significantly $(-42 \%,-39 \%$, respectively; $\mathrm{p}<0.01, \mathrm{n}=216)$. (B) T-47D adhesion was significantly inhibited by HPV16 (-15.9\%) and HPV18 (-15.1\%), as measured by modified 30 -minute adhesion assays $(\mathrm{p}<0.05, \mathrm{n}=72)$.

\section{HPV induced differential changes in MCF7 cell prolifera-} tion

Transfection of the MCF7 cells with HPV16 reduced proliferation (-9.9\%), while HPV18 stimulated proliferation $(+10.4 \%)$ in comparison to non-transfected controls $(\mathrm{p}<0.05, \mathrm{n}=216)$ (Figure 4A). Two-tailed $t$-tests and one-way ANOVA confirmed this differential response was statistically significant between both experimental groups and the controls.

In contrast to the differential response in proliferation observed following HPV transfection, no significant changes to adhesion were observed in MCF7 cells (Figure 4B). Analysis of cellular viability revealed only minor, non-significant reductions in cellular viability between the HPV-transfected MCF7 cells and controls (Table 1).
HPV induced minor changes to adhesion in the normal breast cell line, MCF10A

To contextualize the HPV-induced changes in the setting of breast cancer phenotypes that were observed, the responses of a non-cancerous cell line were also assayed using the normal human breast cell line, MCF10A. These experiments found no significant differences between transfected (HPV16 or HPV18) and non-transfected cells (Figure 5A). Two-tailed t-tests and ANOVA were used to confirm that no statistical significance was evident between these groups.

Although HPV exhibited no significant effects on the growth or proliferation of MCF10A cells, cellular adhesion and viabil-

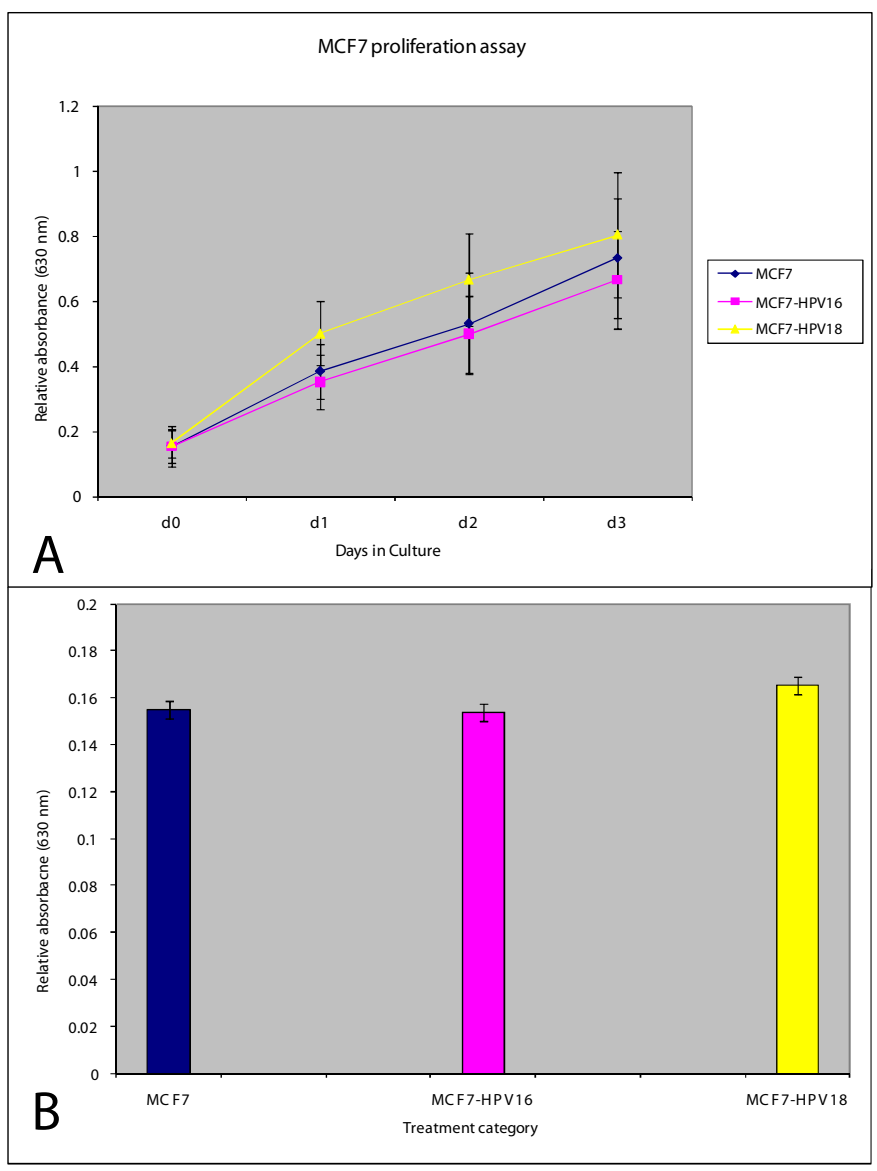

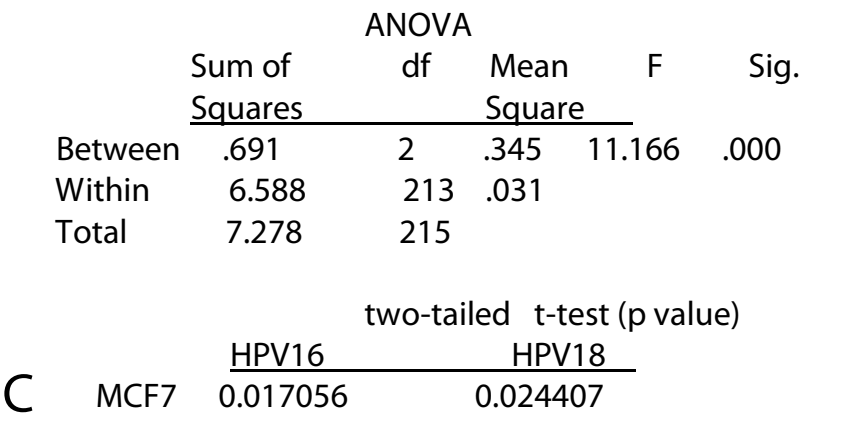

Figure 4: Proliferation of MCF7 cells, but not adhesion, was differentially influenced by HPV16 or HPV18 in vitro.

HPV-transfected and control MCF7 cells were plated in 96-well assay plates with media containing $10 \%$ FBS and were allowed to proliferate for three days. (A) HPV16-transfected cell proliferation was significantly inhibited (-9.9\%), while HPV18-transfected cell proliferation was significantly enhanced $(+10.4 \%)$ $(\mathrm{p}<0.05, \mathrm{n}=216)$. (B) MCF7 cell adhesion was not significantly affected by HPV16 $(-0.6 \%)$ or HPV18 (+6.8\%), as measured by modified 30 -minute adhesion assays $(\mathrm{p}>0.05, \mathrm{n}=72)$.

J Cancer Sci Ther 
Citation: Kingsley K, Zuckerman J, Davis M, Matteucci M, Knavel A, et al. (2009) Induction of Differential Growth in vitro by Highrisk Human Papillomavirus in Human Breast Cancer Cell Lines is Associated with Caspase Dysregulation. J Cancer Sci Ther 1: 062071. doi:10.4172/1948-5956.1000010

\begin{tabular}{|c|c|c|c|c|}
\hline \multirow{2}{*}{$\begin{array}{l}\text { Baseline } \\
\text { viability } \\
\text { (non- } \\
\text { transfected) }\end{array}$} & \multicolumn{4}{|c|}{ Post-transfection viability: } \\
\hline & HPV16 & $\begin{array}{l}\% \\
\text { change }\end{array}$ & HPV18 & $\begin{array}{l}\% \\
\text { change }\end{array}$ \\
\hline $\begin{array}{l}\text { T-47D: } \\
96.4 \% \\
(136 / 141) \\
\end{array}$ & $\begin{array}{l}94.9 \% \\
(195 / 205)\end{array}$ & $-1.5 \%$ & $\begin{array}{l}96.9 \% \\
(157 / 162)\end{array}$ & $+0.5 \%$ \\
\hline $\begin{array}{l}\text { MCF7: } \\
100 \% \\
(110 / 110)\end{array}$ & $\begin{array}{l}96.2 \% \\
(315 / 325)\end{array}$ & $-3.8 \%$ & $\begin{array}{l}97 \% \\
(198 / 204)\end{array}$ & $-3.0 \%$ \\
\hline $\begin{array}{l}\text { MCF10A: } \\
95.5 \% \\
(173 / 181)\end{array}$ & $\begin{array}{l}89.9 \% \\
(251 / 279)\end{array}$ & $-5.6 \%$ & $\begin{array}{l}91.5 \% \\
(257 / 281)\end{array}$ & $-4.0 \%$ \\
\hline $\begin{array}{l}\text { Hs27: } \\
92.4 \% \\
(208 / 226)\end{array}$ & $\begin{array}{l}87.3 \% \\
(180 / 203)\end{array}$ & $-5.1 \%$ & $\begin{array}{l}95.1 \% \\
(202 / 212)\end{array}$ & $+2.7 \%$ \\
\hline
\end{tabular}

Table 1: Cell viability in control and HPV-transfected cells.

ity assays were also performed to assess if other behaviors were affected. Unlike growth and proliferation, cellular adhesion of MCF10A cells was significantly altered by HPV16 $(+9.5 \%$, $\mathrm{p}<0.01, \mathrm{n}=144)$ and HPV18 (+11.06\%, $\mathrm{p}<0.01, \mathrm{n}=144)$ compared with non-transfected controls (Figure 5B), although no differences in viability were observed (Table 1).

\section{HPV induced minor changes to adhesion in the normal fi- broblast cell line, Hs27}

To further compare and contrast the HPV-induced phenotypic that were observed between the cancerous and non-cancerous cells tested, the responses of another non-cancerous cell line were also assayed using the normal human fibroblast cell line, Hs27. The results revealed no significant differences between the proliferation of Hs27 cells transfected with HPV16 or HPV18 and non-transfected Hs 27 controls ( $>>0.05$, n=72) (Figure 6A). Two-tailed $t$-tests confirmed no statistical differences in proliferation were found between the groups (Hs27-HPV16, p>.05; Hs27-HPV18, p>.05). ANOVA confirmed there were no significant differences between or within the experimental and control groups.

In addition to testing the effects of HPV16 and HPV18 on the proliferation of $\mathrm{Hs} 27$ cells, cellular adhesion and viability were assessed. Adhesion of the non-transfected Hs27 cells was significantly inhibited by HPV16 $(-19.25 \%, \mathrm{p}>0.05, \mathrm{n}=72)$ but not by HPV18 $(+13.12 \%, \mathrm{p}>0.05, \mathrm{n}=72)$ (Figure 6B). In addition, no significant changes in viability were observed with Hs27HPV16 or HS27-HPV18 transfectants (Table 1).

\section{RT-PCR}

Researchers have established that the principle tumorigenic activity of HPV early genes, including E6, may be the targeting, subsequent degradation, and down regulation of the tumor suppressor p53 (Scheffner et al., 1990; Sun et al., 2008). Because damaged genes and other molecular pathways in cancerous cells may involve deactivation of key tumor suppressors, such as p53, total RNA was extracted from cells and relative endpoint (RE) RT-PCR was performed to assess p53 expression in these cells (Figure 7). Wild type p53 expression was

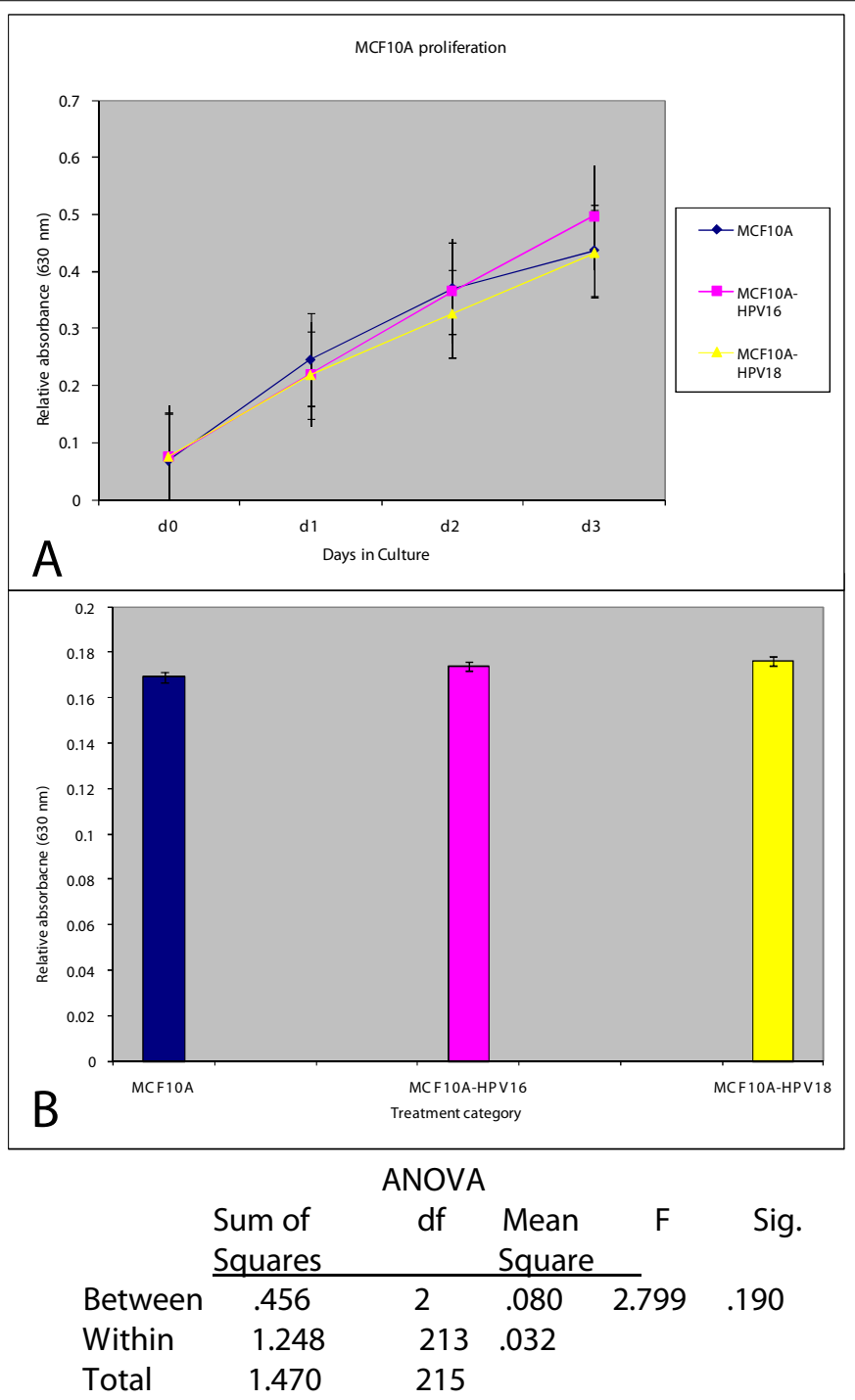

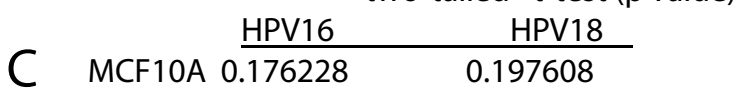

Figure 5: HPV16 and HPV18 did not significantly alter MCF10A phenotypes in vitro.

HPV-transfected and control MCF10A cells were plated in 96-well assay plates with media containing $10 \%$ FBS and were allowed to proliferate for three days. (A) HPV16- and HPV18-transfected cell proliferation was similar and not significantly different from control cells ( $\mathrm{p}>0.05, \mathrm{n}=216)$. (B) MCF10A cell adhesion was significantly enhanced by HPV16 (+9.5\%) and HPV18 (+11.06\%), as measured by modified 30 -minute adhesion assays $(\mathrm{p}<0.05, \mathrm{n}=72)$.

observed in both T-47D (Figure 7A) and MCF7 (Figure 7B) breast cancer cell lines, confirming earlier observations (Ho et al., 2005; Parssinen et al., 2008). The expression levels of p53 mRNA, however, were not significantly altered by HPV16 or HPV 18 transfection in either cell line over the time course of these assays (Day 3 shown; Figure 7A, B), as was recently demonstrated in some oral cancer cell lines transfected with HPV (Chatelain et al., 2008).

Recently, other studies have suggested that HPV viral genome amplification may also be dependent upon caspase-mediated cleavage within the infected cells, which in turn may influence differentiation and cellular replication rates (Moody et al., 2007; 


\section{Journal of Cancer Science \& Therapy - Open Access \\ JCST/Vol.1 Issue 2}

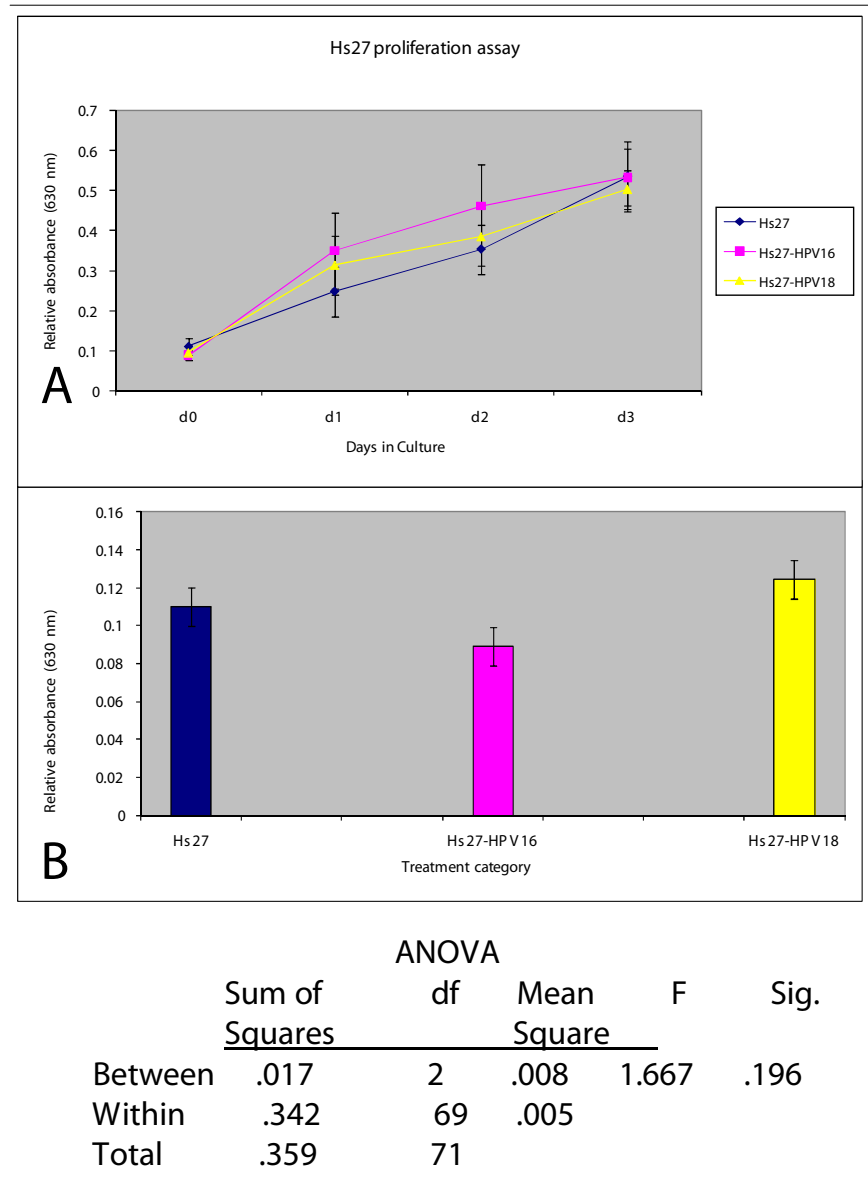

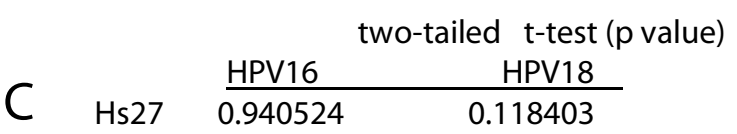

Figure 6: HPV16 and HPV18 did not significantly alter Hs27 phenotypes in vitro.

HPV-transfected and control Hs27 cells were plated in 96-well assay plates with media containing $10 \%$ FBS and were allowed to proliferate for three days. (A) HPV16- and HPV18-transfected cell proliferation was similar and not significantly different from control cells ( $p>0.05, n=216$ ). (B) Hs27 cell adhesion was significantly inhibited by HPV16 (-19.25\%), but not by HPV18 (-13.12\%), as measured by modified 30-minute adhesion assays $(\mathrm{p}>0.05, \mathrm{n}=72)$.

Coelho et al., 2008). (RE) RT-PCR was performed to determine if the effects of HPV16 and HPV18 transfection on these cells correlated with differential expression of specific members of the caspase family (Figure 7). In sharp contrast to p53 expression, marked increases in the expression of caspase-2, 3 , and-8 mRNA were observed in T-47D cells following HPV transfection (Figure 7A). MCF7 cells, however, exhibited differential responses to HPV transfection (Figure 7B), with HPV16 reducing and HPV18 stimulating caspase-2 mRNA expression levels. Interestingly, caspase-3 mRNA expression was undetectable in this cell line and no significant changes in caspase-8 mRNA were observed in either cell line. No changes to mRNA expression levels were observed in Hs27 or MCF10A cells (data not shown).

To quantify the relative changes in mRNA expression levels from the experimental and control groups, scanning densitometry was performed. Specifically, HPV16 increased expression of the apoptosis initiators caspase-2 $(+28.55 \%)$ and caspase- 3 $(+47.55 \%)$, as well as the apoptosis-effector caspase- 8
$(+32.02 \%)$ in T-47D cells; HPV18 also increased expression of caspase-2 $(+26.37 \%)$, caspase $-3(+53.87 \%)$ and caspase- 8 $(+50.63 \%)$, revealing that caspase mRNA expression levels were significantly altered by HPV16 or HPV18, but not levels of p53 or GAPDH mRNA. The differential response of MCF7 cells, however, revealed that HPV16 reduced expression of caspase$2(-14.5 \%)$, while HPV18 increased caspase- 2 mRNA expression $(+18.34 \%)$.

\section{Discussion}

Persistent infection with high-risk, oncogenic HPV strains has been firmly established as the primary cause of virtually all cases of cervical cancer (Walboomers et al., 1999; Castellsague, 2008). In contrast, ample evidence now confirms that HPV is present in a subset of oral cancers and more recently, in breast cancers that may be unrelated to carcinogenesis (Kan et al., 2005; de Villiers et al., 2005; Kreimer et al., 2005; Syrjanen, 2005). Some evidence now suggests that HPV infection in these tissues may contribute to, rather than directly cause, the malignancy or transformation process.

For example, a recent study explored the potential roles of HPV in breast cancer patients. This study revealed that approximately two-thirds of normal epithelial tissue samples taken from sites adjacent to HPV16-expressing breast carcinomas also contained HPV16 DNA (Khan et al., 2008), suggesting that HPV may have induced transformation in the larger subset of these

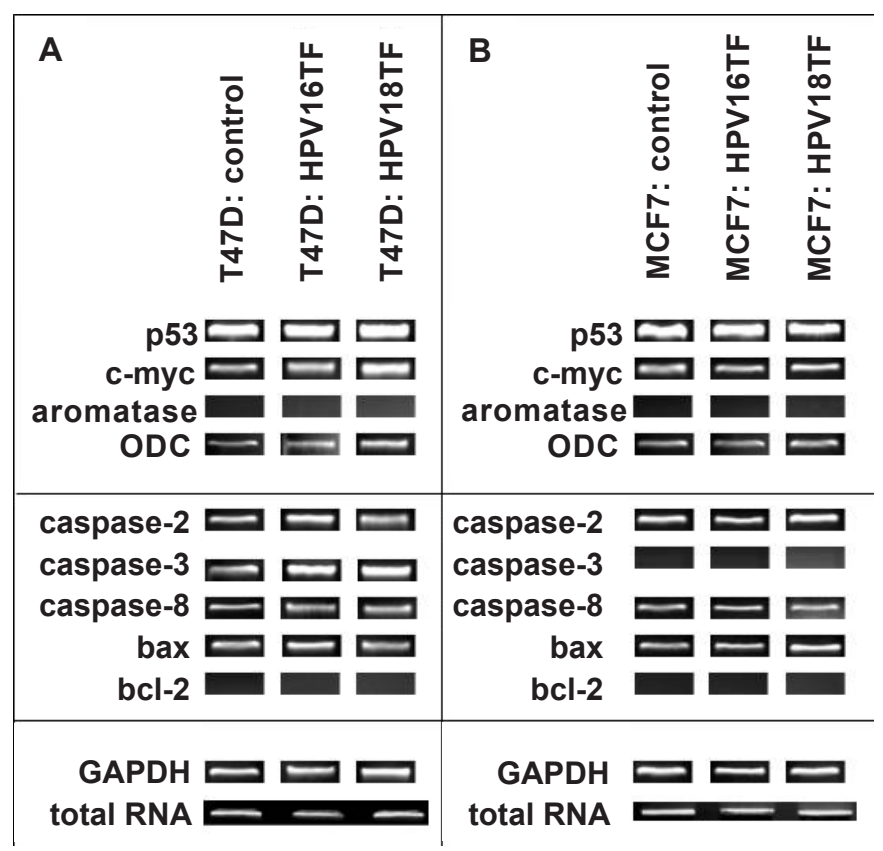

Figure 7: T-47D and MCF7 mRNA analysis.

RT-PCR was performed on total RNA extracted from $10^{7}$ T-47D (A) and MCF7 (B) cells at 24 and 48 hours (data not shown), and 72 hours. Relative endpoint (RE) RT-PCR revealed that $\mathrm{p} 53$ and GAPDH expression levels remained relatively constant pre- and post-transfection in both cell lines. HPV16 and HPV18 significantly enhanced expression of caspase- $2,-3$ and -8 in T-47D cells (A), while no significant changes were noted in MCF7 cells (B). Note: caspase-3 mRNA was undetectable in MCF7 cells at all time points. Scanning densitometry was performed from RE-RT-PCR results, revealing HPV16 increased expression of caspase- $2(+28.55 \%)$, caspase- $3(+47.55 \%)$, and caspase- 8 $(+32.02 \%)$ in T-47D cells; MCF7 cells exhibited a differential response, with HPV16 reducing expression of caspase-2 (-14.5\%) and HPV18 increasing caspase- 2 mRNA expression $(+18.34 \%)$; no significant measurable differences in caspase-8 mRNA were evident.

J Cancer Sci Ther
Volume 1(2) : 062-071 (2009) - 068 
Citation: Kingsley K, Zuckerman J, Davis M, Matteucci M, Knavel A, et al. (2009) Induction of Differential Growth in vitro by Highrisk Human Papillomavirus in Human Breast Cancer Cell Lines is Associated with Caspase Dysregulation. J Cancer Sci Ther 1: 062071. doi:10.4172/1948-5956.1000010

breast cancer patients. However, these data also provide strong evidence that HPV was not involved in the etiology of the smaller subset, which did not contain any discernable evidence of a localized HPV infection. Although many studies suggest that specific oncogenic HPV strains may be present in up to half of breast cancer biopsies, few studies to date have investigated the possibility that HPV infection may, in fact, mediate specific phenotypes associated with the malignancy process (Kan et al., 2005; de Villiers et al., 2005). This study is among the first to provide direct evidence that HPV is capable of modulating the proliferative phenotypes of existing breast cancers.

Based upon results from other studies demonstrating HPV mediates the proliferative phenotypes of oral cancers (Kingsley et al., 2006; Reddout et al., 2007), the current study investigated whether high-risk HPV16 and HPV18 strains induce significant and measurable changes in breast cancer phenotypes, strain is sufficient to alter growth rates in both of the breast vious evidence has demonstrated that HPV16 and HPV 18 were sufficient to immortalize a normal human mammary epithelial cell line, these studies were not designed to explore the possibility that HPV might have differential effects in already transformed cells (Band et al. 1990). Moreover, previous studies of HPV-mediated effects on normal cell lines, including human foreskin keratinocytes and normal breast tissues, were designed to assay HPV-induced immortalization, or escape from senescence, rather than the relative proliferation or turnover rates of 1999). Finally, new evidence is emerging which suggests HPV infection in some oral cancers may actually increase patient survival under certain conditions, suggesting a clinical correlation with these differential proliferative responses (Fischer et al., 2009; Jung et al., 2009).

The experimental design of this study was employed specifically to reveal the presence of differential responses, not only between the cell lines, but also between different HPV strains within the same cell line. These data now suggest complex inter-relationships between the effects of HPV infection and intrinsic cellular or cytogenetic differences. Moreover, these results bear some resemblance to previous work from this laboratory that demonstrated these high risk HPV strains do not elicit equivalent responses among all oral cancer cell lines tested, and that different HPV strains may inhibit or increase cell proliferation within the same cell line (Reddout et al., 2007).

HPV elicits cellular responses as part of the transformation process in cervical epithelia, yet those specific responses were not observed in the breast cancer cell lines in this study. For instance, HPV viral replication proteins influence cellular proliferation in most cervical cancers by inactivating degrading, and subsequently down regulating tumor suppressor proteins, such as p53 (Scheffner et al., 1990; Werness et al., 1990). However, in this study, HPV transfection did not significantly alter p53 expression in either breast cancer cell line, which may seem at odds with the evidence from cervical cancers.

Recent work now confirms that many viruses have evolved alternative mechanisms to inhibit p53 function. For example, p53 deactivation may occur via site-specific serine phosphoryincluding proliferation. The results indicated that either HPV cancer cell lines examined, but not normal cells. Although prethese cells in culture (Band et al., 1990; Hawley-Nelson et al.,

lation in some cells without mRNA down regulation (Shin et al., 2006; Sun et al., 2008). Data indicating that wild-type p53 expression was not reduced by HPV transfection in these breast cancers might suggest that HPV in these cell lines may instead utilize other mechanisms, such as phosphorylation-mediated inactivation of p53. Future studies are now planned to explore these potential mechanisms.

Although deregulation or deactivation of p53 and other tumor suppressors may be critical to the mechanisms of the HPV life cycle, other work has demonstrated that HPV viral genome amplification may also be dependent upon caspase-mediated functions within infected cells (Moody et al., 2007; Coelho et al., 2008). These studies reveal that the productive viral life cycle of HPV is significantly enhanced by caspase-mediated cleavage that may, in fact, be integral to the HPV viral life cycle. Aside from their incidental involvement in the HPV life cycle, caspases function primarily as potent activators of cellular apoptosis and are known to inhibit cellular proliferation. Caspase up-regulation and proliferation inhibition have also been observed in previous work using cervical cancer cells (Moody et al., 2007; Coelho et al., 2008; Singh and Singh, 2008). Intriguingly, the anti-cancer mechanism of Taxol (Paclitaxel), a potent treatment for ovarian, lung and breast cancers, was recently determined to involve activation of members of the caspase family, more specifically caspase-8 (Lee et al., 2005).

Despite the growing evidence that high-risk HPV strains are present in many breast tumors, few studies have examined the ability of HPV to modulate cellular phenotypes in these cancers. Although epidemiologic studies suggest other risk factors, such as genetic predisposition and tobacco or alcohol use, are likely responsible for breast oncogenesis, new evidence suggests concomitant HPV infection may significantly alter tumor growth. This study provides direct evidence that HPV16 and HPV 18 can modulate the proliferative phenotypes in existing breast cancer cell lines, although more research is needed to understand the complex inter-relationships between the observed effects of HPV infection and specific intrinsic or cytogenetic differences that control this phenomenon. Determining the effects of HPV on already transformed breast cancers is thus an important step towards understanding the factors that will ultimately lead to more accurate prognosis and more effective treatment options for breast cancer patients with concomitant HPV infections.

\section{Acknowledgements}

This research was supported by a Research Development Award (RDA) to KK from the UNLV Office of Research Services. KK would like to thank Laurel Pritchard, Kenneth Fernandez and Chandler Marrs for their invaluable assistance with the editing of this manuscript.

\section{References}

1. Band V, Zajchowski D, Kulesa V, Sager R (1990) Human papilloma virus DNAs immortalize normal human mammary epithelial cells and reduce their growth factor requirements. Proc Natl Acad Sci USA 87: 463-467. » CrossRef » PubMed » Google Scholar

2. Castellsague X (2008) Natural history and epidemiology of HPV infection and cervical cancer. Gynecol Oncol 110: S4-7. »CrossRef » PubMed » Google Scholar 


\section{Journal of Cancer Science \& Therapy - Open Access JCST/Vol.1 Issue 2}

3. Chatelain K, Phippen S, McCabe J, Teeters CA, O’Malley S, et al. (2008) Cranberry and grape seed extracts inhibit the proliferative phenotype of oral squamous cell carcinomas. Evid Based Complement Alternat Med [Epub ahead of print]. » CrossRef » PubMed » Google Scholar

4. Coelho RA, Focchi GR, Nogueira-de-Souza NC, Sartori MG, Silva ID, et al. (2008) Prognostic markers of low-grade squamous intraepithelial lesions: the role of topoisomerase II alpha and active caspase-3. Eur J Gynaecol Oncol 29: 499-501. » CrossRef » PubMed » Google Scholar

5. Dean A (2008) Primary breast cancer: risk factors, diagnosis and management. Nurs Stand 22: 47-55. » CrossRef » PubMed » Google Scholar

6. de Villiers EM, Sandstrom RE, Hausen ZH, Buck CE (2005) Presence of papillomavirus sequences in condylomatous lesions of the mammillae and in invasive carcinoma of the breast. Breast Cancer Res 7: R1-R11. » CrossRef » PubMed » Google Scholar

7. Felsher DW, Zetterberg A, Zhu J, Tisty T, Bishop JM (2000) Overexpression of MYC causes p53-dependent G2 arrest of normal fibroblasts. Proc Natl Acad Sci USA 97: 10544-10548. » CrossRef » PubMed » Google Scholar

8. Fischer CA, Zlobec I, Green E, Probst S, Storck C, et al. (2009) Is the improved prognosis of p16 positive oropharyngeal squamous cell carcinoma dependent of the treatment modality. Int J Cancer [Epub ahead of print]. „ CrossRef » PubMed » Google Scholar

9. Gillison ML, Koch WM, Capone RB, Spafford M, Westra WH, et al. (2000) Evidence for a causal association between human papillomavirus and a subset of head and neck cancers. J Natl Cancer Inst 92: 675-677. » CrossRef $»$ PubMed » Google Scholar

10. Hawley-Nelson P, Vousden KH, Hubbert NL, Lowy DR, Schiller JT (1989) HPV16 E6 and E7 proteins cooperate to immortalize human foreskin keratinocytes. EMBO J 8: 3905-3910. » CrossRef » PubMed » Google Scholar

11. Hays WL (1994) Inferences about population means. In: Statistics $\left(5^{\text {th }}\right.$ edition). International Thomson Publishing 311-342. » CrossRef » PubMed » Google Scholar

12. Herrero R, Castellsague X, Pawlita M, Lissowska J, Kee F, et al. (2003) Human papillomavirus and oral cancer: The International Agency for Research on Cancer multicenter study. J Natl Cancer Inst 95: 1772-1783. »CrossRef » PubMed » Google Scholar

13. Ho CY, Kim CF, Leung KN, Fung KP, Tse TF, et al. (2005) Differential anti-tumor activity of coriolus versicolor (Yunzhi) extract through p53and/or Bcl-2-dependent apoptotic pathway in human breast cancer cells. Cancer Biol Ther 4: 638-644. » CrossRef » PubMed » Google Scholar

14.Jung AC, Briolat J, Millon R, de Reynies A, Rickman D, et al. (2009) Biological and clinical relevance of transcriptionnally active human papillomavirus (HPV) infection in oropharynx squamous cell carcinoma. Int J Cancer [Epub ahead of print]. » CrossRef » PubMed » Google Scholar

15. Kan CY, Iacopetta BJ, Lawson JS, Whitaker NF (2005) Identification of human papillomavirus DNA sequences in human breast cancer. Br J Cancer 93: 946-948. »CrossRef » PubMed » Google Scholar

16. Khan NA, Castillo A, Koriyama C, Kijima Y, Umekita Y, et al. (2008) Human papillomavirus detected in female breast carcinomas in Japan. Br J Cancer 99: 408-414. » CrossRef » PubMed » Google Scholar

17. Kingsley K, Huff JL, Rust WL, Carroll K, Martinez AM, et al. (2002) ERK $1 / 2$ mediates PDGF-BB stimulated vascular smooth muscle cell proliferation and migration on laminin-5. Biochem Biophys Res Commun 293: 1000-1006. » CrossRef » PubMed » Google Scholar

18. Kingsley K, Johnson D, O’Malley S (2006) Transfection of oral squamous cell carcinoma with human papillomavirus-16 induces proliferative and morphological changes in vitro. Cancer Cell Int 6: 14. » CrossRef » PubMed » Google Scholar

19. Kreimer AR, Clifford GM, Boyle P, Franceschi S (2005) Human papillomavirus types in head and neck squamous cell carcinomas worldwide: a systematic review. Cancer Epidemiol Biomarkers Prev 14: 467475. »CrossRef » PubMed » Google Scholar

20. Kugu K, Ratts VS, Piquette GN, Tilly KI, Tao XJ, et al. (1998) Analysis of apoptosis and expression of bcl-2 gene family members in the human and

J Cancer Sci Ther baboon ovary. Cell Death Differ 5: 67-76. » CrossRef » PubMed » Google Scholar

21.Lawson JS, Tran D, Rawlinson WD (2001) From Bittner to Barr: a viral, diet and hormone breast cancer aetiology hypothesis. Breast Cancer Res 3: 81-85. » CrossRef » PubMed » Google Scholar

22. Lawson JS, Gunzburg WH, Whitaker NJ (2006) Viruses and human breast cancer. Future Microbiol 1: 33-51.» CrossRef » PubMed » Google Scholar

23. Lee KH, Yim EK, Kim CJ, Namkoong SE, Um SJ, et al. (2005) Proteomic analysis of anti-cancer effects by paclitaxel treatment in cervical cancer cells. Gynecol Oncol 98: 45-53. » CrossRef » PubMed » Google Scholar

24. Mahoney MC, Bevers T, Linos E, Willett WC (2008) Opportunities and strategies for breast cancer prevention through risk reduction. CA Cancer J Clin 58: 347-71. » CrossRef » PubMed » Google Scholar

25. Moody CA, Fradet-Tucotte A, Archambault J, Laimins LA (2007) Human papillomaviruses activate caspases upon epithelial differentiation to induce viral genome amplification. Proc Natl Acad Sci USA 104: 2954119546. » CrossRef » PubMed » Google Scholar

26. Munoz N, Bosch FX, de Sanjose S, Herrero R, Castellsaque X, et al. (2003) Epidemiologic classification of human papillomavirus types associated with cervical cancer. N Engl J Med 348: 518-527. »CrossRef » PubMed » Google Scholar

27.Parssinen J, Alarmo EL, Karhu R, Kallioniemi A (2008) PPM1D silencing by RNA interference inhibits proliferation and induces apoptosis in breast cancer cell lines with wild-type p53. Cancer Genet Cytogenet 182: 33-39. »CrossRef » PubMed » Google Scholar

28. Plopper GE, McNamee HP, Bojanowski K, Ingber DE (1995) Convergence of integrin and growth factor receptor signaling pathways within the focal adhesion complex. Mol Biol Cell 6: 349-1365. » CrossRef » PubMed » Google Scholar

29. Reddout N, Christensen T, Bunnell A, Jensen D, Johnson D, et al. (2007) High risk HPV types 18 and 16 are potent modulators of oral squamous cell carcinoma phenotypes in vitro. Infect Agent Cancer 2: 21. » CrossRef » PubMed » Google Scholar

30. Ruiz-Ruiz C, Ruiz de Almodovar C, Rodriguez A, Ortiz-Ferron G, Redondo JM, et al. (2004) The up-regulation of human caspase- 8 by interferongamma in breast tumor cells requires the induction and action of the transcription factor interferon regulatory factor-1. J Biol Chem 279: 1971219720. »CrossRef » PubMed » Google Scholar

31. Scheffner M, Werness BA, Huibregtse JM (1990) The E6 oncoprotein encoded by human papillomavirus types 16 and 18 promotes the degradation of p53. Cell 63: 1129-1136. » CrossRef » PubMed » Google Scholar

32. Shin YC, Nakamura H, Liang X, Feng P, Chang H, et al. (2006) Inhibition of the ATM/p53 signal transduction pathway by Kaposi's sarcomaassociated herpesvirus interferon regulatory factor I. J Virol 80: 2257-2266. »CrossRef » PubMed » Google Scholar

33. Singh M, Singh N (2008) Induction of apoptosis by hydrogen peroxide in HPV 16 positive human cervical cancer cells: involvement of mitochondrial pathway. Mol Cell Biochem 310: 57-65. » CrossRef » PubMed » Google Scholar

34. Smith JS, Lindsay L, Hoots B, Keys J, Franceschi S, et al. (2007) Human papillomavirus type distribution in invasive cervical cancer and high-grade cervical lesions: a meta-analysis update. Int J Cancer 121: 621-632.» CrossRef » PubMed » Google Scholar

35. Sun L, Zhang G, Li Z, Song T, Huang C, et al. (2008) In GFP with high risk HPV-18E6 fusion protein expressed 293T and MCF-7 cells, the endogenous wild-type p53 could be transiently phosphorylated at multiple sites. J Clin Exp Clin Cancer Res 27: 35. » CrossRef » PubMed » Google Scholar

36. Syrjanen S (2005) Human papillomavirus (HPV) in head and neck cancer. J Clin Virol 32: s59-66. » CrossRef » PubMed » Google Scholar

37. Tsai JH, Hsu CS, Tsai CH, Su JM, Liu YT, et al. (2007) Relationship between viral factors, axillary lymph node status and survival in breast cancer. J Cancer Res Clin Oncol 133: 13-21. » CrossRef » PubMed » Google Scholar

38. Vakifahmetoglu H, Olsson M, Orrenius S, Zhivotovsky B (2006) Func- 
Citation: Kingsley K, Zuckerman J, Davis M, Matteucci M, Knavel A, et al. (2009) Induction of Differential Growth in vitro by Highrisk Human Papillomavirus in Human Breast Cancer Cell Lines is Associated with Caspase Dysregulation. J Cancer Sci Ther 1: 062071. doi:10.4172/1948-5956.1000010

tional connection between p53 and caspase-2 is essential for apoptosis induced by DNA damage. Oncogene 25: 5683-5692. » CrossRef » PubMed » Google Scholar

39. van Houten VM, Snijders PJ, van den Brekel MW, Kummer JA, Meijer CJ, et al. (2001) Biological evidence that human papillomaviruses are etiologically involved in a subgroup of head and neck squamous cell carcinomas. Int J Cancer 93: 232-235. » CrossRef » PubMed » Google Scholar

40. Wagner JE, Huff JL, Rust WL, Kingsley K, Plopper GE (2002) Perillyl alcohol inhibits breast cell migration without affecting cell adhesion. J Biomed Biotechnol 2: 136-140. » CrossRef » PubMed » Google Scholar

41. Walboomers JMM, Jacobs MV, Manos MM, Bosch FX, Kummer JA, et al. (1999) Human papillomavirus is a necessary cause of invasive cervical cancer worldwide. J Pathol 189: 12-19. » CrossRef » PubMed » Google Scholar

42. Werness BA, Levine AJ, Howley PM (1990) Association of human papillomavirus types 16 and 18 E6 proteins with p53. Science 248: 76-79. »CrossRef » PubMed » Google Scholar

43. Wolter F, Turchanowa L, Stein J (2003) Resveratrol-induced modification of polyamine metabolism is accompanied by induction of c-Fos. Carcinogenesis 24: 469-474. »CrossRef » PubMed » Google Scholar

44. Yasmeen A, Bismar TA, Kandouz M, Foulkes WD, Desprez PY, et al. (2007) E6/E7 of HPV type 16 promotes cell invasion and metastasis of human breast cancer cells. Cell Cycle 6: 2038-2042. »CrossRef » PubMed » Google Scholar

45. Yasmeen A, Bismar TA, Dekhil H, Ricciardi R, Kassab A, et al. (2007) ErbB-2 receptor cooperates with E6/E7 oncoproteins of HPV type 16 in breast tumorigenesis. Cell Cycle 6: 2939-2943. »CrossRef » PubMed » Google Scholar 